\title{
Collaborative Supply Chain Management: The Hybrid Knowledge-Based Development Approach of Suppliers-Customers Perspective
}

\author{
Zulkifli Mohamed Udin \\ College of Business, Universiti Utara Malaysia, \\ 06010 UUM SINTOK, Kedah Darul Aman, MALAYSIA \\ Email: zulkifli@uum.edu.my \\ Shahimi Mohtar \\ College of Business, Universiti Utara Malaysia, \\ 06010 UUM SINTOK, Kedah Darul Aman, MALAYSIA \\ Email : shahimi@uum.edu.my \\ Abdul Aziz Othman \\ College of Business, Universiti Utara Malaysia, \\ 06010 UUM SINTOK, Kedah Darul Aman, MALAYSIA \\ Email: abdaziz@uum.edu.my
}

\begin{abstract}
Using a hybrid methodology (Knowledge Based, GAP analysis and AHP approach), the Knowledge-Based CSCM (KBCSCM) system was developed to assist in planning and designing a Collaborative Supply Chain Management (CSCM). The KBCSCM system has a capability to identify variables or factors that need to be improved immediately for supply chain collaboration development. The purpose of this paper is to discuss the approach / methodology that used to identify the key components that are need to be improved in developing a CSCM from the supplier and customer perspective. This paper also demonstrates the use of The Gauging Absence of Prerequisites (GAP) analysis and Analytic Hierarchy Process (AHP) technique that are embedded in the KBCSCM system, which is used to support the CSCM development. This paper deals with the perspective of auto parts suppliers and customers in the automotive industry on the ability to work together among suppliers, Original Equipment Manufacturers (OEMs) and customers in supply chain management (SCM). A case study approach has been used to gather data from 150 respondents in 8 different organisations through KBCSCM system. A series of questions was initially asked, followed by interviews to confirm the answers from respondents. By utilising GAP analysis and AHP technique, management could use the result to design the supply chain collaboration environment. The GAP analysis technique, which embedded in the knowledge-based system, is proposed to analyse the gap between the current and the desirable position (benchmark) for an effective implementation. The proposed framework enables suppliers and customers to identify key factors or issues that have greater improvement priority for supply chain collaboration development.
\end{abstract}

Keywords: Supply Chain Management, Collaboration, Expert System, GAP Analysis, Supplier-Customer

\section{Introduction}

In the current era of dynamic markets, cost reduction is not the only factor that could help organisations to gain and sustain their competitive advantage.
Other factors such as improving customer's service levels, delivery times and quality along with improvement in the supplier-customer relationship are major contributors to the Original Equipment 
Manufacturer's (OEM's) competitiveness. OEMs should plan a new strategy by considering these factors in developing a collaborative or integrated Supply Chain Management (SCM) in order to improve or sustain their organisation competitiveness through the SCM capability.

Collaborative Supply Chain Management (CSCM) is a strategy to gain competitiveness for organisations (Peterson and Cecere, 2001). It should be noted that CSCM had evolved since 1990's (Barratt and Oliveira, 2001), and was motivated by earlier approaches such as Just-In-Time (JIT), Electronic Data Interchange (EDI) and Quick Response (QR). CSCM implementation does not only enables the smoothness of information sharing and exchanging, but also it prepares a platform for sharing knowledge, risks and profits as stressed by Chandra and Kumar (2001). This view is supported by Mentzer et al. (2000) when describing CSCM as:

"All companies in the supply chain that are actively working together as one toward common objectives by sharing information, knowledge, risk and profits which could involve on how other companies operate and make decisions."

They also make the point that the implementation of CSCM requires all players (suppliers, OEMs, customers) to develop mutual trust between them as a foundation in their suppliercustomer relationship. Akintoye et al. (2000) describes this attitude as the basic principle in any strategic partnership between suppliers and customers, which was also the key factor to form supply chain collaboration. Furthermore, Simatupang and Sridharan (2008) addressed that supply chain collaboration is a vehicle to facilitate players to improve individual and chain group performance.

This paper identifies and focuses only one of the components in the CSCM development framework, which is Supplier-Customer Strategy. Actual data was collected from eight companies as a case study through series of questions, which conducted using the Knowledge-Based Collaborative Supply Chain Management (KBCSCM) system, a novel approaches in the SCM discipline (Udin, 2004). The paper then discusses how these sub-components are used to evaluate the current status of relationship between players in the supply chain by utilising the Gauging
Absence of Pre-requisites (GAP) analysis (Kochhar et al. 1991) and Analytic Hierarchy Process (AHP) (Saaty, 1982). Both techniques are embedded KBCSCM system as core mechanism in this system. The results are analysed to identify the most distinct variables or factors for improvement purposes before collaboration can be realised. Finally the conclusion of this paper emphasises the capability of Hybrid KBCSCM system to support the management in the CSCM development from suppliers and customers perspective.

\section{Building the CSCM Conceptual Framework}

In the supply chain collaboration, all players or organisations (suppliers, OEMs and customers) in the supply chain should work together as one organisation and move toward a common objective, taking a responsibility in sharing and exchanging common planning, forecasting, performance measurement and management of information (Anthony, 2000; Mentzer et al., 2000). These capabilities are pre-requisite to make the supply chain work effectively in this collaborative environment. Apart from that, the infrastructure or technologies that enable organisations to collaborate with their suppliers and customers are also required in order to optimise the use of information that flows throughout the chain (Anthony, 2000). Therefore, in developing a CSCM, an appropriate amount of planning and design is needed in order to make it functioned effectively and efficiently (Udin, 2004).

The CSCM framework differs significantly in three research aspects (Udin, 2004). Firstly, in the SCM environment, this framework focuses on the development of collaborative SCM. The main differences between Transactional SCM (TSCM) and CSCM is related to the development of a 'win-win situation' relationship between suppliers, organisations (OEMs) and customers. These players work together as partners rather than industry rivals, by sharing information and technology, exchanging expertise and sharing responsibility, which contribute to cost and waste reduction, quality enhancement and delivery improvement. Secondly, in the CSCM framework it is more comprehensive, by considering all activities in the 
internal and external chains of organisations. Compared to previous works, most studies are focused on procurement activities, which related to supplier selection, make or buy decisions and supplier quality. The CSCM framework comprehensively covers all activities that relate to the internal and external chains, which are believed to be a pre-requisite in developing CSCM. In developing CSCM, the emphasised should be on internal chain factors such as human development, technology enhancement, process improvement, functional integration, value and culture establishment, and top management commitment (Burgess et al., 1997; Akintoye et al., 2000; Mentzer et al., 2000; Temkin, 2002), and external chain factors such as relationship improvement, sharing environment development and communication enhancement (Ellinger, 2000; Baliga, 2001; Stank et al., 2001; Yu et al., 2001; Cokins, 2002). And lastly, the CSCM framework is different to previous researches relates to the additional techniques that are embedded either in the model or during development processes. Two techniques are embedded in the KB development: Gauging Absence of Pre-requisites (GAP) analysis and Analytic Hierarchy Process (AHP). Hence, the use of a hybrid KB-GAP-AHP methodology provides a detailed qualitative and quantitative methodology to identify key areas of prioritised decision-making. Even though Razmi et al. (1998) and Chan (2002) have thoroughly explored the use of AHP in KBS, the utilisation of a hybrid methodology (KBS, GAP analysis and AHP technique) in the area of SCM has not yet been used (Udin, 2003a; 2004).

The framework for CSCM development is divided into three stages with focus to the planning stage, which is a basis for the development (Udin, 2006a). The utilisation of a Knowledge-Based System (KBS) throughout the framework adds an advantage in planning and designing a CSCM, as depicted in Figure 1.

In the Planning Stage, the Organisation Environment component is used to gather the information that relates to general information and organisation background of the company that is being analysed. The function of this component is to identify organisations in industry in which they are involved. In addition, one of the pre-requisites

Figure 1. The Planning stage Framework of CSCM Development (Udin, 2004)

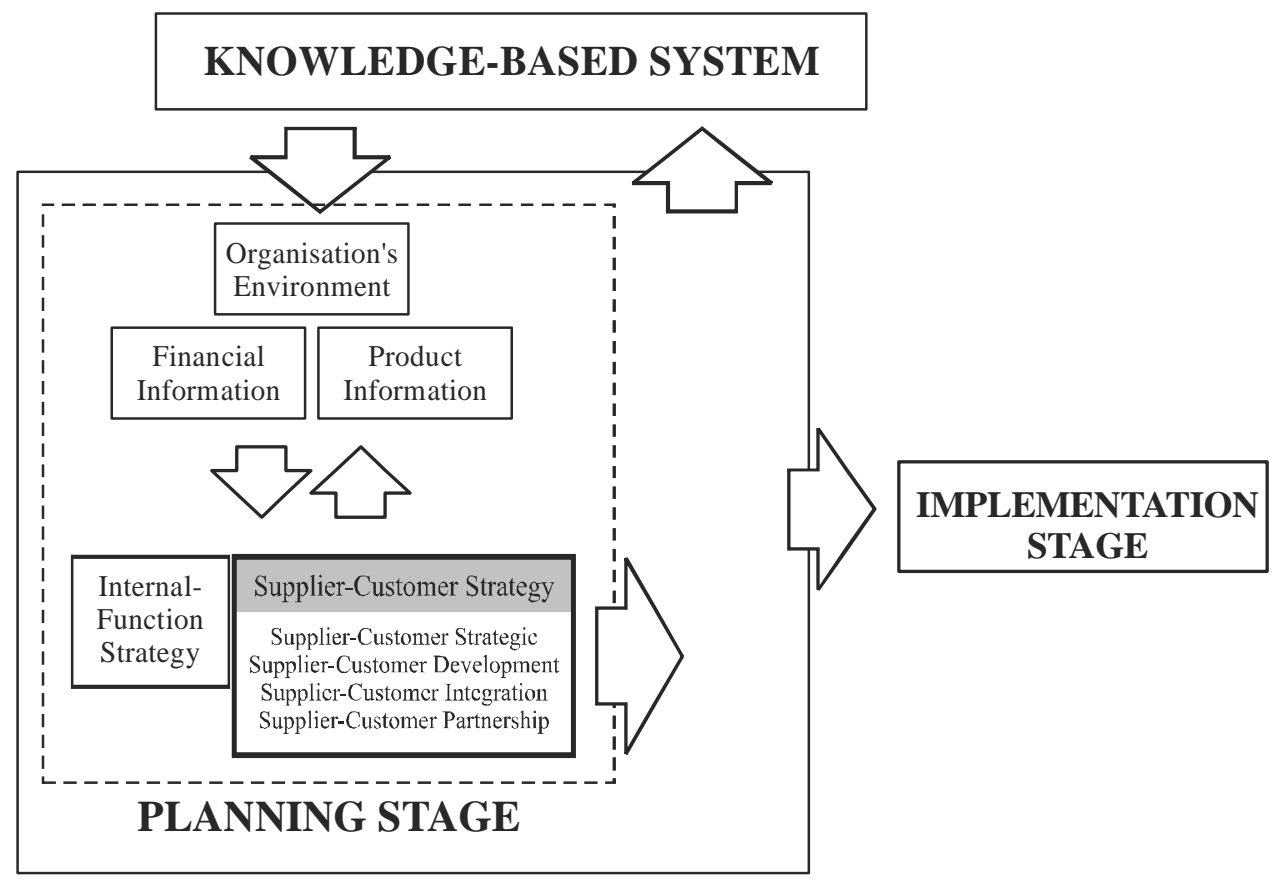


for organisations to evaluate their suppliers or customers is based on their financial information status, since suppliers and customers must be ready and able to share costs that are unexpectedly incurred such as cost of uncertainty demand and supply, machine breakdown, and products return in the CSCM environment. Measuring the organisation financial performance is important for the top management in order to understand their organisation's current position in the industry before any decision can be made at the supply chain. Rockstroh (2002) identified that the financial conditions play an important role, along with quality and delivery speed, to face challenges in the global market. This is in line with Brunnermeier and Martin (2002) who stressed the importance of improving the efficiency of the supply chain through factors that relate to the organisation's financial position.

The Product Information component gathers all data related to the organisation's products such as product types, product design and development, and production strategy. Yeh (2000) noted that the product data are needed in order for organisations to make a strategic decision, such as deciding on production planning or planning for new technology installation. Products play an important role in determining organisations' competitiveness and the percentage of their market share. Beside, it also captures suppliers' and customers' information to measure their involvement in product development activities. Twigg (1998) summarises the dimension of supplier involvement, which include contribution from suppliers, level of involvement, stages in product development and components supplied. This dimension could help OEMs in selecting potential suppliers, which are not only based on the offered price, but also consider other important factors such as product development lead-time, delivery schedule time, delivery quality and reliability.

The Internal Function Strategy component is developed to identify the functional activities in the organisation's internal supply chain. The importance of this component is to investigate and analyse the current position of the organisation's internal function with respect to its supply chain management. This argument is parallel to what has been discussed by Ellinger (2000), Ferguson (2000), and Sarkis and Sundarraj (2000), where the effectiveness and supportiveness of the internal function is the key factor in making organisations work smoothly and successfully in their supply chain. Moreover, any improvement such as resources reallocation, revaluing business process and technology installation in the internal activities could reflect on the effectiveness of the whole SCM.

The Supplier-Customer Strategy component is developed to identify activities in the organisation's external supply chain, which includes several processes that are used in producing products. The importance of this component is to investigate and analyse the current position of suppliers and customers with respect to organisation supply chain management. The relationship between the organisation (OEM) and suppliers-customers is important in the current supply chain as a platform to develop a CSCM (Sahay, 2003). Dyer (1996) highlighted that benefits such as increasing market share, improving delivery, improving quality and reducing cost are not only achieved by the organisation (OEM), they also spread to suppliers and customers as well. This argument has also been discussed by Ellinger (2000), Ferguson (2000) and Sarkis and Sundarraj (2000), who revealed that the changes in the supplier-customer relationship from adversary to co-operative and collaborative relationship is the strategic initiative to make organisations work smoothly and successfully in their supply chain.

The focus in the planning stage framework is to discuss about the Supplier-Customer Strategy component as highlighted in Figure 1. In this component, there are four sub-components to assess the ability of suppliers and customers to collaborate in the supply chain, namely; Supplier-Customer Strategic (SCS), Supplier-Customer Development (SCD), Supplier-Customer Integration (SCI) and Supplier-Customer Partnering (SCP). The importance of these sub-components is to investigate and analyse the current position of suppliers and customers with respect to organisation supply chain management. Based on these data, the potential supplier and customer for supply chain collaboration development could be identified. As discussed by Handfield and Ernest (1999) and Ferguson (2000), the potential supplier and customer are players that are willing and capable to work together in terms of sharing risk, profit, responsibility and information. Each of these sub-components is described in the following section. 


\subsection{Supplier-Customer Strategic}

Supplier-Customer Strategic refers to the top-level issue in developing a relationship between supplier and customer. The most important issue that influences the success or failure of this relationship is the commitment from all players in the supply chain. In viewing this issue, Zineldin and Jonsson (2000) stressed, "Commitment is an enduring desire to maintain a valued relationship". This is because, through commitment, all players in the supply chain dedicate their resources to sustain and further the goals of the supply chain (Spekman et al.1998). Thus, to maintain relationship, both supplier and customer must understand thoroughly the relationship goals in order to prevent any difficulties in the future. This is parallel to Jonsson and Zineldin (2003) findings that mentioned commitment can only evolve in the organisation after members in that organisation understand the vision, mission, goal and objective of that organisation and some actions towards commitment development is implemented. Furthermore, suppliers and customers must realise commitment is something that could not be forced or imposed. It is something that evolves through discussion and communication between supplier and customer (Udin, 2003a; 2004). In this study, the commitment issue is measured by evaluating the responses from these players through number of questions that relate to their roles in the supply chain relationship.

\subsection{Supplier-Customer Development}

The second sub-component is related to the development of the relationships involving teams, training programme and incentive schemes. Bal and Gundry (1999) reported that almost 95 per cent of respondents utilised team working in their projects to produce automotive parts in the Rover Group supply chain. This percentage showed the importance of team development in supply chain to improve the effectiveness of supplier-customer relationship, and at the same time improving the quality of design and reducing product lead-time. According to Burt et al. (2003), developments of teams (which consist of several members from supply chain players) have become more important in implementing World Class Supply Management. It is believed that by implementing teams, whether cross-functional teams or cross-organisation teams, the development of
CSCM could be foster effectively. By developing teams between suppliers, OEMs and customers, this could increase the commitment and trust among them. Additionally, in team development, players in the supply chain should adopt a suitable and appropriate training programme to ensure the effectiveness of teams. The joint training programme should involve suppliers, OEMs or customers for the purpose of developing the team spirit along with the development of other values such as sharing environment, trust, and commitment (Udin, 2003a; 2004).

\subsection{Supplier-Customer Integration}

The third sub-component is related to the integration of information and communication that exists in the supplier-customer relationship. The current status of linkages between supplier and customer is evaluated by assessing the supplier capability in responding to customer demands. Through integration, supplier and customer could work together closely to achieve better financial results, highest customer service level and excellent product quality (Udin, 2003b; 2004). Furthermore, players in the supply chain could also deliver their expertise among themselves in certain areas or activities in the supply chain. The integration in supplier-customer relationship could take place in various activities in supply chain such as purchasing, product design, logistics or distribution, which involves human resources, production capability or other resources. In order to accelerate this integration, the main factor that needs to be remedied in this relationship is communication and information (Chandra and Kumar (2000). For example, by utilising the right information along with the capable communication technology, suppliers and customers would have capability to handle the changes in supply-demand and able to make a plan for future transaction. In addition, Cassivi (2006) concluded that information visibility also seen as a critical element in maintaining an efficient supply chain which can be obtained through the plan and execution of supply chain collaboration in both upstream and downstream players.

\subsection{Supplier-Customer Partnering}

The fourth sub-component in the Strategic SupplierCustomer component relates to partnering process, partnering success factors and partnering 
satisfaction. These variables are important to evaluate in order to identify the real factors that contribute in the supplier-customer relationship of CSCM. The partnering process describes the behaviour that supports the close relationship between players in the supply chain (Udin, 2004). In addition, it also identifies the factors that exist in the building of long-term relationship amongst these players. According to Spekman et al. (1998), the sustainability of relationship for a period of time depends on how suppliers and customers view this relationship among them. The partnering success factor merely emphasises on how supplier, OEM and customer promote trusting and sharing behaviour in their relationships (Udin, 2004). Factors (such as trust and dependability) in these variables are important and critical in developing CSCM as discussed by many researchers such as Lambert et al. (1999), Hoyt and Huq (2000) and Mentzer et al. (2000). Finally, in this sub-component, the satisfaction of supplier-customer is evaluated through identification of elements in the supplier and customer satisfaction programme implemented in their organisation.

\section{Methodology}

The Knowledge-Based System (KBS) is used to support in gathering all information from respondents before being analysed using The Gauging Absence of Prerequisites (GAP) analysis and Analytic Hierarchy Process (AHP) technique, which embedded in the KBS (Udin, 2006b). In the KBCSCM system, the rule-base KBS or ES is selected to support the planning and designing of CSCM due to the following factors such as most mature technique, many commercial shell and development tools available to support the development, and the process of building the system is comparatively simple compared to other AI techniques. The rule-base KBS is used in structuring the knowledge and information compiled from literature and interactive session with users (respondents). In this study, respondents are selected from managerial level (managers and executives) of every functional area in each organisation with total of 60 peoples. Each of them answered series of questions that related to their functions in the organisation using the nominal scale (Yes or No) format, which is suitable for the GAP analysis technique utilisation. Through GAP analysis, the requirement of main elements for CSCM implementation can be revealed. In addition, GAP analysis provides a quantitative basis for comparing the status in the present condition with future requirement for the effective functioning of CSCM. The GAP analysis in the KBCSCM System is conducted based upon users' responses to the questions provided. The problems highlighted for each negative reply (respondent's answer is No) are classified into five categories, which are structured in descending order of importance (Kochhar et al., 1991) and shown in Table 1.

In Table 1, the code is used to identify whether the responses given by users are in the Good Point Category (user's answer is 'Yes') or Bad Point Problem Category (PC) (user's answer is 'No'). The Problem Category is ranked from 1 to 5 , with the latter PC-5 being the least critical condition. Based on the GAP analysis technique, only the Bad Points are categorised into Problem Categories, due to the aim of the system, which enables it to identify the

Table 1. Problem Categories and Description of GAP Analysis Technique (adapted from Kochhar et al., 1991)

\begin{tabular}{|c|c|c|}
\hline Category & Code & \multicolumn{1}{c|}{ Description } \\
\hline 1 & PC-1 & $\begin{array}{l}\text { This indicates a serious problem, which should and can be resolved in the short term and the result of the problem is quite } \\
\text { likely to provide a real short-term benefits. } \\
\text { This indicates a serious problem, which is likely to have pre-requisites and is better dealt with as part of an appropriate and } \\
\text { logical improvement and implementation plan. } \\
\text { This is not a serious problem and can be dealt with now. If resolved, it is likely to produce short-term benefits. } \\
3\end{array}$ \\
\hline & PC-2 \\
5 & PC-3 & $\begin{array}{l}\text { This is not a serious problem. Although it could be dealt with now, it is unlikely to produce short-term benefits. Therefore, it } \\
\text { should only be dealt with if it is a pre-requisite for other things. } \\
\text { This is not really a Good or Bad point it self. The questions associated with this category are primarily asked to identify certain } \\
\text { situations in the environment, which upon subsequent probing by succeeding questions may well reveal probl }\end{array}$ \\
\hline
\end{tabular}


missing pre-requisites that are needed for successful implementation of CSCM. Through this result, the missing pre-requisites of the current position of suppliers, OEMs and customers can be identified through the number of Bad Points. Based on series of questions that have been analysed by the GAP analysis technique, the AHP technique is been used to prioritise the factors that are needed for improvement. According to Razmi (1998), AHP is a powerful tool, which can be used to deal with complex multi-attributes problems, particularly in selecting and prioritising alternatives for improvement purposes. The utilisation of hybrid approach requires specific algorithms in the process to match the five-point scales of Problem Categories (PC) in the GAP analysis before the Priority Vector calculation process for each variable or factor take place.

A brief example of the KBS rules that represent series of questions in the Supplier-Customer Strategic sub-component and their description are as follows:

IF the OEM agrees that the SC relationship goal has been clearly defined (Good Point)

AND fully understood the supply chain relationship goal (Good Point)

AND fully agreed with the supply chain relationship goal (Good Point)

AND there is no opportunity to discuss in developing the supply chain relationship goal (Bad Point -Problem Category 1)

AND there is no opportunity to participate in developing the supply chain relationship goal (Bad Point-Problem Category 1)

AND there is no opportunity to review in developing the supply chain relationship goal (Bad PointProblem Category 1)

THEN the OEM achieved 3 Good Point and 3 Problem Category 1 for the supply chain relationship commitment

Based on the example, the tested variables are related to the supply chain relationship commitment. In this case, respondent achieved 3 Good Points (which answer is Yes) and 3 Bad Point (in the Problem Category 1). Based on Table 1, this organisation has serious problem related to people involvement in supply chain relationship goal development, which need to be resolved immediately in order to gain benefits from it. All answers (Good and Bad Points) are calculated at the end of each-subcomponent through GAP analysis technique. All Bad Points are transformed into the scale Intensity of Importance in the AHP technique in order to show the Priority Vector of each sub-component (or sub-module). Based on this result, the management could identify which variables or factors that have greater improvement priority and used them to support in designing the appropriate collaborative supply chain environment for their organisation

\subsection{KBCSCM System Structure}

From the information system development perspective, the structure of the KBCSCM system is shown in Figure 2. Based on this structure, a clear relationship is shown between components in the Planning and Design Stage of the CSCM conceptual framework by dividing them into number of perspectives. These perspectives were developed according to their relevance to the CSCM development, based on elements or variables from previous SCM literatures. The KBCSCM system is developed in the knowledge-based environment, based on the capability of the AM Enterprise development software and each components is viewed either as module, submodule or procedure (Udin, 2004).

A GAP analysis was embedded in the knowledgebased system and designed to provide a number of user-friendly facilities as described in following sections.

\subsubsection{Interactive Questions}

The series of interactive questions are developed for user to answer in a stepwise manner. All questions are written in a simple and clear sentence, to prevent the user from misunderstanding the issues of the questions. Based on the user responses and question issues, those questions may have sub-questions in the sub-windows.

\subsubsection{Facility Answer}

Depending on the content and context, a question can be answered with Yes or No response. If the user answers 'Yes', then the program will execute the subquestion of related question, otherwise the answer will be indicated with Problem Category point before proceed to the next question. Each negative answer has been prioritised in terms of importance, through categorisation of the problem into five broad areas (Problem Category 1 to 5) as discussed earlier. 
Figure 2. Structure of KBCSCM System

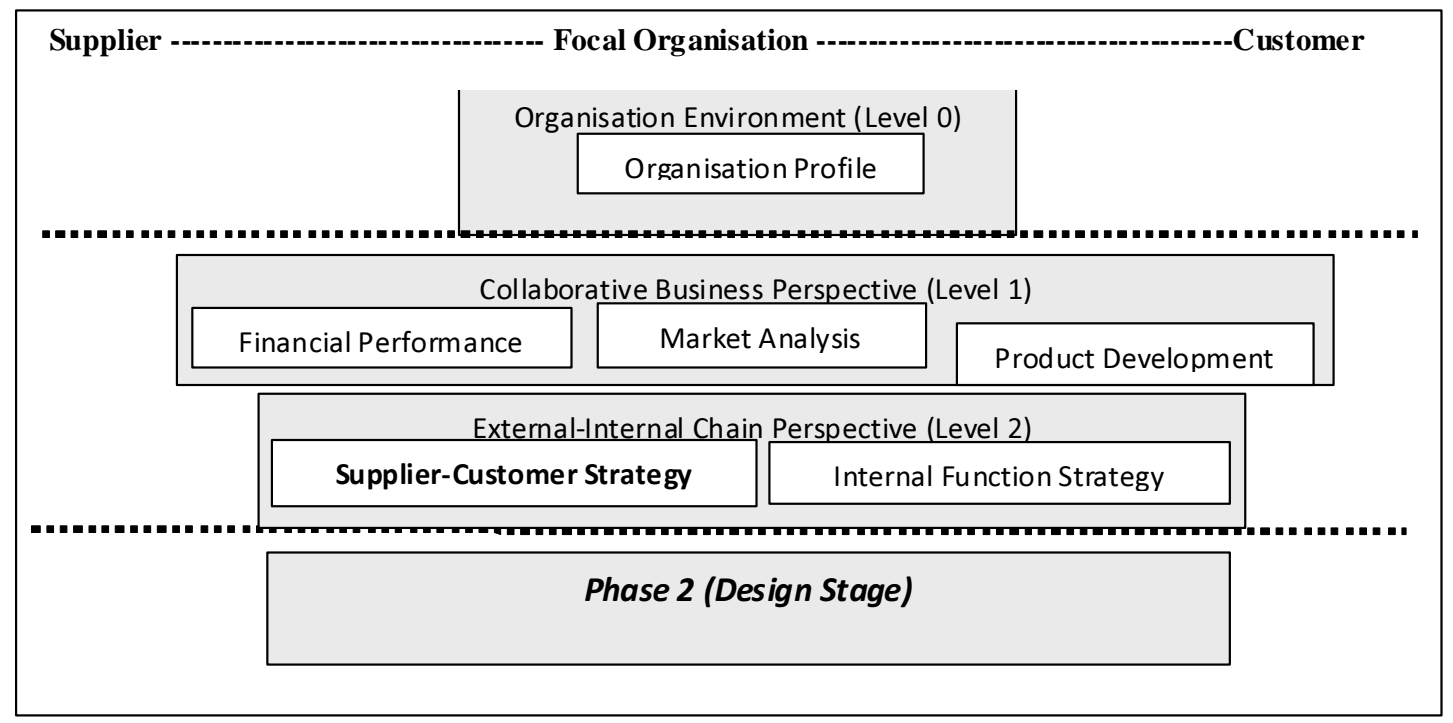

\subsubsection{Explanation of Question}

The Explanation facility that is built into the $\mathrm{KBCSCM}$ program is a very important part of the system. Additional knowledge is added in the explanation windows that could assist the user to understand the issues of the question and the consequences from the issues. All questions are phrased as unambiguously as possible in order to avoid misinterpretation, which could lead to an incorrect answer and finally would affect the diagnosis driven by the GAP analysis. The explanation also provides an indication of good practices that should be implemented in the organisation.

\subsection{Case Study Approach}

The case study approach was considered to be the most appropriate for the study to get rich data on the implementation of SCM in the automotive industry. This is supported by Yin (1994), the use of case method could offer in depth understanding on the situation, information, and details in results. The practices of SCM by each organisation were captured through series of questions in the KBCSCM system and interviews. As described earlier, this case study involved eight organisations and respondents represented from every functional areas of each organisation. The purposive sampling was used, which resulted in total of 150 individuals (managers and executives) involved in this case study. There are two main phases in conducting this study. Firstly, it involved data collection process and secondly, data and model validation process. The duration of both phases is about 1 year. The next section of the paper discusses the findings, which out of eight, three cases in SC activities are presented, as an example.

\section{Findings and Discussions}

The assessment in the KBCSCM Model is conducted through sequential questions that measure information based on the GAP analysis. The GAP analysis is used to identify the differences between the current status of organisation and what actually exists in that organisation. Based on the results from the GAP analysis, the KBCSCM processes the results using the AHP approach, as introduced by Saaty (1982), to determine which variables, subcomponent or components should be in priority of improvement and how the weight of priority between variables from supplier-customer perspective. In this study, the GAP analysis provides the priorities actions needed internally (in terms of Problem Category) while the AHP output provides the prioritised actions externally (between sub-modules, sub-components or components).

As mentioned earlier, the data used in this paper is collected from the both phases, which carried out 
in one automotive manufacturer in the South-East Asia. This involved the OEM (focal organisation, known here as OEM-A), two first-tier suppliers, four second-tier suppliers and one first-tier customer. In this paper, results from the validation of OEM-A are used as an example to illustrate the KBCSCM model ability and shown in Table 2.

Table 2 shows an example of user response on Supplier-Customer Module. There are a total of 18 questions asked on Supplier-Customer Strategic subcomponent, 26 questions for Supplier-Customer Development sub-component, 55 questions for Supplier-Customer Integration sub-component and 86 questions for Supplier-Customer Partnering subcomponent. From 185 questions of SupplierCustomer Component, the OEM-A achieved 151 Good Points and 34 Problem Category (PC) that consist of 7 PC1, 11 PC2, 6 PC3, 5 PC4 and 0 PC5. Except in the Supplier-Customer Strategic sub-module, which assesses OEM-A commitment itself, all questions that were asked are solely related to OEM-A relationship with its supplier and customer only. Almost all submodules do not have any significant differences in the relationship between OEM-A-supplier and the relationship between OEM-A-customer except in the Satisfaction aspect in the Supplier-Customer Partnering sub-module. In this aspect, there are 18 questions for supplier and 25 questions for customer. There are 5 Problem Category present in OEM-A-supplier relationship in terms of satisfaction while 12 Problem Category arise in OEM-A-customer relationship in terms of satisfaction. From this number, it shows that the relationship between OEM-A is better with its supplier compared to its customer. This result also indicates that OEM-A probably has a problem in its downstream supply chain, which relates to distribution activities and post-sales services. Handfield and Nichols (1999) noted that the supply chain downstream activities are OEM's window to customers. Problems that arise in these activities could reflect and affect the relationship between OEM and customers. Morash (2001) who supported this argument asserted that by improving downstream activities and staying close to customer, the OEM could sustain the relationship with its customer's better and longer period. This was due to services

Table 2. Summary of GAP Analysis for Supplier-Customer Perspectives Module from OEM-A

\begin{tabular}{|c|c|c|c|c|c|c|c|c|c|c|}
\hline \multirow{2}{*}{ Sub Module } & \multirow{2}{*}{ Aspect } & \multirow{2}{*}{$\begin{array}{l}\text { Supply Chain } \\
\text { Players }\end{array}$} & \multirow{2}{*}{$\begin{array}{l}\text { Number of } \\
\text { Question }\end{array}$} & \multirow{2}{*}{$\begin{array}{l}\text { Good } \\
\text { Points }\end{array}$} & \multicolumn{6}{|c|}{ Bad Points - Problem Category Achieved } \\
\hline & & & & & Total & 1 & 2 & 3 & 4 & 5 \\
\hline \multirow{4}{*}{$\begin{array}{l}\text { Supplier- } \\
\text { Customer } \\
\text { Strategic }\end{array}$} & \multirow[t]{3}{*}{ Commitment } & Supplier & 6 & 6 & 0 & 0 & 0 & 0 & 0 & 0 \\
\hline & & Organisation & 6 & 3 & 3 & 3 & 0 & 0 & 0 & 0 \\
\hline & & Customer & 6 & 6 & 0 & 0 & 0 & 0 & 0 & 0 \\
\hline & \multicolumn{2}{|l|}{ TOTAL } & 18 & 9 & 3 & 3 & 0 & 0 & 0 & 0 \\
\hline \multirow{7}{*}{$\begin{array}{l}\text { Supplier- } \\
\text { Customer } \\
\text { Development }\end{array}$} & \multirow[t]{2}{*}{ Teams } & Supplier & 3 & 3 & 0 & 0 & 0 & 0 & 0 & 0 \\
\hline & & Customer & 3 & 3 & 0 & 0 & 0 & 0 & 0 & 0 \\
\hline & \multirow[t]{2}{*}{ Training } & Supplier & 5 & 5 & 0 & 0 & 0 & 0 & 0 & 0 \\
\hline & & Customer & 5 & 5 & 0 & 0 & 0 & 0 & 0 & 0 \\
\hline & \multirow[t]{2}{*}{ Incentive } & Supplier & 5 & 3 & 2 & 0 & 0 & 2 & 0 & 0 \\
\hline & & Customer & 5 & 4 & 1 & 0 & 0 & 1 & 0 & 0 \\
\hline & \multicolumn{2}{|l|}{ TOTAL } & 26 & 23 & 3 & 0 & 0 & 3 & 0 & 0 \\
\hline \multirow{5}{*}{$\begin{array}{l}\text { Supplier- } \\
\text { Customer } \\
\text { Integration }\end{array}$} & \multirow[t]{2}{*}{ Linkages } & Supplier & 20 & 18 & 2 & 0 & 2 & 0 & 0 & 0 \\
\hline & & Customer & 15 & 12 & 3 & 0 & 1 & 1 & 1 & 0 \\
\hline & \multirow{2}{*}{\begin{tabular}{|l|} 
Information \& \\
Communication \\
\end{tabular}} & Supplier & 10 & 7 & 3 & 0 & 1 & 2 & 0 & 0 \\
\hline & & Customer & 10 & 7 & 3 & 1 & 0 & 2 & 0 & 9 \\
\hline & \multicolumn{2}{|l|}{ TOTAL } & 55 & 44 & 11 & 1 & 4 & 5 & 1 & 0 \\
\hline \multirow{7}{*}{$\begin{array}{l}\text { Supplier- } \\
\text { Cus t om er } \\
\text { Partnering }\end{array}$} & \multirow[t]{2}{*}{ Process } & Supplier & 17 & 17 & 0 & 0 & 0 & 0 & 0 & 0 \\
\hline & & Customer & 15 & 15 & 0 & 0 & 0 & 0 & 0 & 0 \\
\hline & \multirow[t]{2}{*}{ Success Factors } & Supplier & 6 & 6 & 0 & 0 & 0 & 0 & 0 & 0 \\
\hline & & Customer & 5 & 5 & 0 & 0 & 0 & 0 & 0 & 0 \\
\hline & \multirow[t]{2}{*}{ Satisfaction } & Supplier & 18 & 13 & 5 & 1 & 3 & 1 & 0 & 0 \\
\hline & & Customer & 25 & 13 & 12 & 2 & 4 & 2 & 4 & 0 \\
\hline & \multicolumn{2}{|l|}{ TOTAL } & 86 & 69 & 17 & 3 & 7 & 3 & 4 & 0 \\
\hline & \multicolumn{2}{|l|}{ GRAND TOTAL } & 185 & 151 & 34 & 7 & 11 & 6 & 5 & 0 \\
\hline
\end{tabular}


Table 3. AHP Analysis:-Intensity of Importance and Priority Vector for Supplier-Customer Perspective

\begin{tabular}{|c|c|c|c|c|c|}
\hline Sub-Module & SCS & SCD & $\mathrm{SCl}$ & SCP & $\begin{array}{l}\text { Priority } \\
\text { Vector }\end{array}$ \\
\hline $\begin{array}{l}\text { Supplier-Customer) } \\
\text { Strategic (SCS }\end{array}$ & 1 & 2 & 1 & 1 & 0.29 \\
\hline $\begin{array}{l}\text { Supplier-Customer } \\
\text { Development (SCD) }\end{array}$ & $1 / 2$ & 1 & 1 & 1 & 0.21 \\
\hline $\begin{array}{l}\text { Supplier-Customer } \\
\text { Integration (SCI) }\end{array}$ & 1 & 1 & 1 & 1 & 0.25 \\
\hline $\begin{array}{l}\text { Supplier-Customer } \\
\text { Partnering (SCP) }\end{array}$ & 1 & 1 & 1 & 1 & 0.25 \\
\hline \multicolumn{5}{|l|}{ TOTAL } & 1.00 \\
\hline
\end{tabular}

that are delivered to customers. In the other situation, OEM-A would face a big problem if this dissatisfaction is related to their products. If the problem occurred, OEM-A should check its production activities and moves to upstream level of supply chain. OEM-A should make assessment of its supplier in terms of raw materials or parts that are delivered to OEM-A.

Table 3 shows the result of the Intensity of Importance between these four sub-modules and the Priority Vector as a result conducted by the AHP module of the system.

Based on this table, the Priority Vector for SCS is 0.29 , for the SCD is 0.21 while SCI and SCP are both 0.25 respectively. This means that, based on the GAP analysis and AHP process embedded in the system, OEM-A should place its improvement priority first on the SCS, which relates to the commitment on the relationships among supplier, OEM and customer. This is followed with an improvement for SCI and SCP, which has a similar priority and lastly, an improvement should be done in SCD that consists of team development, training and incentives scheme, which could be assumed as currently having a good situation and should maintain its position.

Based on these validation results, the analysis of the supplier-customer perspectives shows that the condition that currently exist in this relationship has potential to support the development of collaborative SCM between OEM-A and its supplier and customer. The OEM-A should take an immediate action on particular area such as improving satisfaction with its customer by assessing the downstream activities or directly examine their products. In addition, improvement should be done on particular areas as suggested by the KBCSCM system through the capability of AHP technique.

\section{Practical Implications and Conclusions}

There are some important implications for practitioners and researchers drawn from this study. This paper described the use of new and novel approach, known as hybrid approach (Knowledge Based, GAP analysis and AHP technique), and the KBCSCM system. The KBCSCM could assist management to focus on variables or factors that need to be improved through prioritizing results for planning and designing a CSCM. This hybrid system performed detailed analysis of the supplier, OEM and customer current condition and suggested the priority area for improvement, for example, the Supplier-Customer Strategic involvement (SCS), which relates to the commitment given to the relationships among supplier, OEM and customer. In the validation process, based on an industrial application, the KBCSCM system showed its capability to identify variables or factors that should be given priority for improvement by organisation. Referring to the example shown in the previous section, the result from the validation process showed that through the capability of the KBCSCM system, the management definitely will be able to identify variables or components that need improvement, together with the quantitative figures to justify their decision. In addition, the applicability of the CSCM conceptual model has been supported by the study. However, the practicality of this approach could further be explored by conducting future research, for instance by distinguishing between before and after implementation of supply chain collaboration using some indicators such as Return of Investment (ROI), Customer Satisfaction Index (CSI) or Collaboration Index (CI). This, in turn, will contribute to a deeper understanding about the advantages of supply chain collaboration. 


\section{References}

Akintoye, A., McIntosh, G. and Fitzgerald, E. (2000). A survey of supply chain collaboration and management in the UK construction industry, European Journal of Purchasing E Supply Management, 6, pp. 159-168.

Anthony, T. (2000). Supply chain collaboration: success in the new internet economy, http://www.ascet.com.

Bal, J. and Gundry, J. (1999). Virtual teaming in the automotive supply chain, Team Performance Management: An International Journal, 5(6), pp. 174-193.

Baliga, J. (2001). Supply chain collaboration: will determine future success, Semiconductor International, (January), pp. 81-86.

Barratt, M. and Oliveira, A. (2001). Exploring the experiences of collaborative planning initiatives, International Journal of Physical Distribution E Logistics Management, 31(4), pp. 266-289.

Brunnermeier, S. B. and Martin, S. A. (2002). Interoperability costs in the US automotive supply chain, Supply Chain Management: An International Journal, 7(2), pp. 71-82.

Burgess, T. F., Gules, H. K. and Tekin, M. (1997). Supplychain collaboration and success in technology implementation, Integrated Manufacturing Systems, 8(5), pp. 323-332.

Burt, D. N., Dobler, D. and Starling, S.L. (2003). World Class Supply Management: The Key to Supply Chain Managment. New York, McGraw-Hill.

Cassivi, L. (2006), Collaboration planning in a supply chain, Supply Chain Management: An International Journal, 11(3), pp. $249-258$

Chan, F. T. S. (2002). Design of material handling equipment selection system: an integration of expert system with analytic hierarchy process approach, Integrated Manufacturing Systems, 13(1), pp. 58-68.

Chandra, C. and Kumar, S. (2000). Supply chain management in theory and practice: a passing fad or a fundamental change?, Industrial Management and Data Systems, 100(3), pp. 100-113.

Chandra, C. and Kumar, S. (2001). Enterprise architectural framework for supply-chain integration, Industrial Management and Data Systems, 101(6), pp. 290-303.

Cokins, G. (2002). A collaboration enabler: sharing profit and cost data, http://www.ascet.com.

Dyer, J. H. (1996). How Chrysler created an American Keiretsu, Harvard Business Review, 74(4), pp. 42-56.

Ellinger, A. E. (2000). Improving marketing/logistics crossfunctional collaboration in the supply chain, Industrial Marketing Management, 29, pp. 85-96.

Ferguson, B. R. (2000). Implementing supply chain management, Production and Inventory Management Journal, 41(2), pp. 64-67.

Handfield, R. B. and Nichols, Ernest L. (1999). Introduction to Supply Chain Management, London, Prentice Hall.

Hoyt, J. and Huq, F. (2000). From arms-length to collaborative relationships in the supply chain: an evolutionary process, International Journal of Physical Distribution E Logistics Management, 30(9), pp. 750-764.

Jonsson, P. and Zineldin, M. (2003). Achieving high satisfaction in supplier-dealer working relationships, Supply Chain Management: An International Journal, 8(3), pp. 224-240.

Kochhar, A. K., Suri, A. K. and Hather, R. (1991). Design and implementation of a general purpose knowledgebased gap analysis system with particular reference to the implementation of effective material requirements planning systems, IMechE, C429/051, pp. 129-133.

Lambert, D. M., Cooper, M. C. and Pagh, J.D. (1998). Supply chain management: implementations issues and research opportunities, The International Journal of Logistics Management, 9(2), pp. 1-18.

Mentzer, J. T., Foggin, J. H. and Golicic, S.L. (2000). Collaboration: the enablers, impediments and benefits, Supply Chain Management Review, September/October, pp. 52-58.

Morash, E. A. (2001). Supply chain strategies, capabilities and performance, Transportation Journal, (Fall), pp. 3754.

Peterson, K. and Cecere, L. (2001). Supply collaboration is a reality - but proceeds with caution, http:// www.ascet.com.

Razmi, J. (1998). An analytic hierarchy process driven knowledge-based system in push, pull and hybrid manufacturing systems, $P h D$ thesis, School of Engineering, University of Bradford.

Rockstroh, J. (2002). Achieving quality ROI across the supply chain, Quality http://www.qualitymag.com, (June), pp. 54-59.

Saaty, T. L. (1982). Decision Making for Leaders, Belmont, CA, Lifetime Learning Publications.

Sahay, B. S. (2003). Supply chain collaboration: the key to value creation, Work Study, 52(2), pp. 76-83.

Sarkis, J. and Sundarraj, R.P. (2000). Factors for strategic evaluation of enterprise information technologies, International Journal of Physical Distribution $\mathcal{E}$ Logistics Management, 30(3/4), pp. 196-220.

Simatupang, T.M. and Sridharan, R. (2008). Design for supply chain collaboration, Business Process Management Journal, 14(3), pp. 401-418.

Spekman, R. E., John. W. K. Jr. and Myhr, N. (1998). An empirical investigation into supply chain management: a perspective on partnership, International Journal of Physical Distribution E Logistics Management, 28(8), pp. 630-650.

Stank, T. P., Keller, S. B. and Daugherty, P.J. (2001). Supply chain collaboration and logistical service performance, Journal of Business Logistics, 22(1), pp. 29-48.

Temkin, B. (2002). Building a collaborative supply chain, http://www.ascet.com

Twigg, D. (1998). Managing product development within a design chain, International Journal of Operations $\mathcal{E}$ Production Management, 18(5), pp. 508-524. 
Udin, Z.M. (2003a). A knowledge-based collaborative supply chain management system: Part 1 - Planning stage framework, Paper presented at the $19^{\text {th }}$ International Conference on CAD/CAM, Robotics and Factories of the Future, Kuala Lumpur, Malaysia.

Udin, Z.M. (2003b). A knowledge-based collaborative supply chain management system: Part 2 - The hybrid KB/GAP analysis system, Paper presented at the $19^{\text {th }}$ International Conference on CAD/CAM, Robotics and Factories of the Future, Kuala Lumpur, Malaysia.

Udin, Z. M. (2004). A hybrid knowledge-based approach for planning and designing a collaborative supply chain management system, PhD Thesis, School of Engineering, Design and Technology, University of Bradford.

Udin, Z.M., Khan, M.K., Zairi, M. (2006a). A collaborative supply chain management framework: Part 1- planning stage, Business Process Management Journal, 12(3), pp. 361-376.
Udin, Z.M., Khan, M.K., Zairi, M. (2006b). A collaborative supply chain management: Part 2- the hybrid KB/gap analysis system for planning stage, Business Process Management Journal, 12(5), pp. 671-687.

Yeh, C.H. (2000). A customer-focused planning approach to make-to-order production, Industrial Management and Data Systems, 100/4, pp. 180-187.

Yin, R. K. (1994). Case Study Research: Design and Methods, $2^{\text {nd }}$ ed. London, Sage.

Yu, Z., Yan, H. and Cheng, T.C.E. (2001). Benefits of information sharing with supply chain partnerships, Industrial Management and Data Systems, 101/3, pp. 114119.

Zineldin, M. and Jonsson, P. (2000). An examination of the main factors affecting trust/commitment in supplierdealer relationship: an empirical study of the Swedish wood industry, The TQM Magazine, 12(4), pp. 245-265

Dr Zulkifli Mohamed Udin is currently a senior lecturer in the Faculty of Technology Management at Universiti Utara Malaysia, where he has taught Supply Chain Management and ICT for 10 years and has supervised about 15. business research projects. He holds an MSC in Management from the jointly programme between Universiti Utara Malaysia and the British Aerospace (Bae) UK and a PhD in Supply Chain Management from the University of Bradford, UK. His research and consultancy interests cover the theoretical and applied aspects of supply chain management, ICT (particularly in Knowledge-Based Systems and Information Systems development), collaboration development and organizational improvement. He has published in a wide range of international and Malaysia journals and proceedings, and recently coauthor in the book QCC in Malaysian Public Services. He has previously worked in private sector organization in Malaysia where he has been involved in ICT projects spanning most sectors of the economy. Currently he undertaking a research project entitled Supply Chain Management in Malaysia Construction Industry which funded by the Construction Industry Development Board of Malaysia.

Dr Shahimi bin Mohtar is an author, lecturer and researcher who studied the operations management since 1997. He holds a Doctor of Business Administration from the University of South Australia, Master of Business Administration from the Ohio University and Bachelor of Science in Mechanical Engineering from the University of Nevada at Reno. He has more than ten years of working experience in electronic and maritime industries. He is a senior lecturer in the Department of Operation Management, Faculty of Technology Management, Universiti Utara Malaysia. He is also the co-author of Introduction to Operation Management book. He lives in Alor Star, Kedah.

Mr Abdul Aziz Othman is currently a lecturer in the School of Business at Universiti Utara Malaysia. He had an experience as product development executive at Assembly Services Sdn Bhd for one year and has spent eight years lecturing in mathematics (calculus) and area related to management of technology. He holds a Master of Business Administration in Management of Technology from the Asian Institute of Technology, Bangkok and Bachelor of Engineering in Mechanical System from the Miyazaki University, Japan. Involved in several consultation projects such as MBAS (Majlis Bandaraya Alor Star) project, Air Utara Indah Sdn Bhd, Koperasi Tunas Muda Sdn Bhd, Jabatan Tenaga Kerja Semenanjung Malaysia, SCM for CIDB etc. 